\title{
Analisis Sensitivitas Usahatani Pembibitan Sapi Potong di Kabupaten Sleman
}

\author{
S. Emawati \\ Jurusan Peternakan, Fakultas Pertanian, Universitas Sebelas Maret \\ Jl. Ir. Sutami 36 A, Kentingan, Surakarta \\ Email:emawati.shanti@gmail.com
}

\section{INTISARI}

Penelitian ini bertujuan untuk menentukan kondisi finansial peternak dengan adanya perubahan harga pedet berdasarkan umur penjualan pada usahatani pembibitan sapi potong. Penelitian dilaksanakan mulai bulan Januari sampai dengan Mei 2007 dengan lokasi di Kabupaten Sleman. Metode penelitian yang digunakan adalah survei untuk mengumpulkan data primer dari responden dan data sekunder dari dinas terkait. Responden diambil secara purposive sampling. Hasil analisis sensitivitas dengan asumsi ada perbaikan manajemen sehingga calving interval 15 bulan dan umur penjualan pedet 18 bulan pada pembibitan sapi potong layak untuk diusahakan dengan nilai kelayakan terbaik adalah jenis sapi Peranakan Limousine dengan nilai net present value $(\mathrm{NPV})=\mathrm{Rp} 14.443 .576,00$, internal rate of return $(\mathrm{IRR})=29,70 \%$ dan benefit cost of ratio $(\mathrm{BCR})=1,84$, selanjutnya sapi Peranakan Simmental dan PO.

Kata kunci : pembibitan sapi potong, analisis sensitivitas

\section{Sensitivity Analysis of Cattle Breeding Farm in Sleman District}

\section{ABSTRACT}

The research was conducted to investigate financial condition of farmers when the calf price was adjusted to sold age of cattle breeding farm. Research was done from January to May 2007, located in Sleman District. Survey methods was done to collect primary data at the farm level and secondary data from related institution. Purposive sampling was applied to sellect farmers' respondent. Based on the assumption that management of cattle, i.e. calving interval could be improved up to 15 months and 18 months of calf selling age, the sensitivity analysis showed that the most feasible investment of beef cattle breeding farm under farmers' condition was achieved when farmers keep Limousine grade cattle with the value of net present value $(N P V)=R p$. 14.443.576,00, internal rate of return (IRR) = $29,70 \%$ dan benefit cost of ratio $(B C R)=1,84$, followed by Simmental and Ongole grade cattle.

Key words : cattle breeding farm, sensitivity analysis

\section{PENDAHULUAN}

Peranan ternak sapi sebagai pemasok daging cukup besar. Populasi sapi di Indonesia selama kurun waktu empat dasawarsa meningkat cukup signifikan rata- rata 6,69 juta ekor selama kurun 1961 sampai 1970, menjadi 11 juta ekor pada tahun 1991 sampai 2006. Peningkatan populasi sapi tersebut bagaimanapun juga belum dapat mencukupi permintaan daging sapi, hal ini ditandai dengan masih 
meningkatnya impor khususnya setelah tahun 1991. Pada tahun 2005 pasokan daging sapi berasal dari impor mencapai $29,36 \%$ dari kebutuhan daging sapi dalam negeri.

Kasus pemotongan betina produktif yang mencapai $70 \%$ dari jumlah ternak betina yang dipotong menimbulkan dampak penurunan populasi sapi potong. Kurangnya kesadaran masyarakat akan hal tersebut mengakibatkan laju perkembangan populasi menjadi terhambat. Semua ini menjadi penyebab ketidakseimbangan antara perkembangan populasi ternak sapi dengan kebutuhan akan daging sapi. Kondisi yang demikian mengindikasikan usaha sapi potong mempunyai peluang pasar yang bagus. Untuk mengurangi pengeluaran devisa negara serta menghindari pemotongan sapi betina produktif perlu dikembangkan usaha pembibitan sebagai pemasok sapi bakalan. Oleh karena itu, perlu adanya pengembangan sapi potong pembibitan sebagai pensuplai sapi bakalan dan mengejar Program Kecukupan Daging tahun 2010 yang telah dicanangkan oleh Direktorat Jenderal Peternakan (Ditjen Peternakan, 2006).

Kemampuan peternak kita dalam memproduksi ternak khususnya untuk bibit masih sangat terbatas karena pada usaha pembibitan sapi potong membutuhkan investasi yang cukup besar bila diukur oleh kemampuan peternak kecil dalam menyediakan modal. Demikian juga jangka waktu menghasilkan cukup lama, membutuhkan luangan waktu untuk memelihara yang relatif panjang. Meskipun demikian secara ekonomi modal atau investasi tidak menjadi masalah apabila suatu usaha profitable atau layak untuk diusahakan. Salah satu parameter indikator kelayakan tersebut adalah analisis sensitivitas.

Analisis sensitivitas dilakukan untuk menguji apakah suatu usaha tetap layak dijalankan pada tingkat harga tertentu dengan menaikkan biaya secara periodik (Irfan, 2006). Oleh karena itu, peneliti tertarik untuk mengadakan penelitian tentang analisis sensitivitas untuk usahatani pembibitan sapi potong. Tujuan dari penelitian adalah untuk menentukan kondisi finansial peternak dengan adanya perubahan harga anak berdasarkan umur penjualan pada usahatani pembibitan sapi potong.

\section{MATERI DAN METODE}

Penelitian dilaksanakan pada bulan Januari sampai Mei 2007 yang berlokasi di Kabupaten Sleman. Materi yang digunakan dalam penelitian ini adalah peternak pembibitan sapi potong di Kabupen Sleman, ternak sapi dan kuesioner.

\section{Metode Penentuan Lokasi}

Metode penentuan lokasi penelitian ditentukan secara sengaja, dengan lokasi contoh penelitian di Kabupaten Sleman dengan pertimbangan bahwa di lokasi tersebut terdapat beberapa kelompok tani ternak. Kelompok tani ternak yang diambil sebagai sampel penelitian ini adalah sebagai berikut :

Tabel 1. Nama dan Alamat Kelompok Tani Ternak

\begin{tabular}{clllc}
\hline \hline No & Nama Kelompok Tani Ternak & \multicolumn{1}{c}{ Desa } & Kecamatan & Jumlah \\
\hline 1 & Sedyo Raharjo, Andini Harjo & Caturharjo & Sleman & 16 orang \\
2 & Andini Gotro, Sido Maju, & Tambakrejo & Tempel & 20 orang \\
& Andini Jaya & & & \\
3 & Sido Rukun, Tlogowono & Jogotirto & Berbah & 12 orang \\
4 & Marangan, Gangsiran & Bokoharjo, & Prambanan & 12 orang \\
& & Madurejo & & \\
\hline
\end{tabular}

Sumber : Data primer terolah, 2007 


\section{Metode Pengambilan Sampel Peternak}

Metode pengambilan sampel peternak dengan purposive sampling yaitu dipilih peternak dikelompok sampel yang telah memelihara induk sapi potong minimal 1 tahun dan pernah beranak. Jumlah sampel yang diambil dalam penelitian adalah 60 responden dengan pengambilan secara proporsional pada setiap kelompok. Pemilihan secara purposive berarti sampel dipilih dan ditetapkan berdasarkan pertimbangan-pertimbangan tertentu yang sesuai dengan tujuan penelitian (Sugiyono, 2006).

\section{Metode Pengambilan Data}

Pengambilan data dilaksanakan dengan metode survey. Data yang diambil adalah data primer dan data sekunder. Data primer diperoleh dari wawancara kepada responden peternak sapi potong dengan menggunakan kuesioner. Data sekunder untuk menunjang data primer diperoleh dari Dinas Pertanian dan Kelautan, Sub Dinas Peternakan Sleman.

\section{Analisis Data}

\section{Koefisien teknis}

Koefisien teknis yang berpengaruh pada biaya dan penerimaan usaha pembibitan sapi potong yaitu calving interval, service per conception, mortalitas dan umur penjualan pedet.

\section{Analisis biaya dan penerimaan}

Biaya yang diperlukan dalam analisis ini adalah biaya investasi dan biaya operasional. Penerimaan diperoleh dari penjualan pedet sebagai produk pokok dan penjualan kotoran sebagai produk sampingan.

\section{Analisis cash flow}

Analisis cash flow yang digunakan dalam analisis ini adalah memperhitungkan nilai output input sesuai dengan koefisien teknis dari pemeliharaan 2 ekor sapi induk berdasarkan umur investasi 7 tahun dengan discount factor $12 \% /$ tahun.

\section{Analisis kriteria kelayakan}

Benefit Cost Ratio (BCR). Variabel yang diperlukan dalam analisis ini adalah gross benefit yang telah dipresent valuekan dengan total cost yang telah dipresent valuekan. Rumus yang digunakan adalah :

Discounted gross benefit

$\mathrm{BCR}=\frac{}{\text { Discounted total cost }}$

(Gittinger, 1986)

Suatu usaha apabila nilai net $\mathrm{B} / \mathrm{C}$ ratio $>1$, maka proyek "go", sedangkan untuk nilai net $\mathrm{B} / \mathrm{C}$ ratio < 1 , maka proyek "no go" (Prawirokusumo, 1990).

Net Present Value (NPV). Variabel yang diperlukan dalam analisis ini adalah benefit dan cost yang telah dipresent valuekan dengan nilai tingkat discount rate. Rumus yang digunakan adalah :

$\mathrm{NPV}=\sum_{\mathrm{t}=1}^{\mathrm{n}} \frac{\mathrm{Bt}-\mathrm{Ct}}{(1+\mathrm{i})^{\mathrm{t}}}$

(Gittinger, 1986)

Keterangan :

$\mathrm{B}_{\mathrm{t}}=$ Benefit/keuntungan kotor yang diperoleh pada tahun $\mathrm{t}$

$\mathrm{C}_{\mathrm{t}}=$ Cost / biaya yang dikeluarkan pada tahun $\mathrm{t}$

$\mathrm{i}=$ tingkat diskonto

$\mathrm{n}=$ umur ekonomi proyek (tahun)

Suatu proyek apabila nilai NPV $>0$, maka proyek tersebut layak dijalankan. Jika NPV $=0$, berarti proyek tersebut mengembalikan persis sebesar social opportunity cost of capital. Jika NPV $<0$, proyek supaya ditolak artinya adanya penggunaan lain yang lebih menguntungkan untuk sumber-sumber yang diperlukan proyek (Kadariah et al., 1999). 
Internal Rate Of Return (IRR). Variabel yang diperlukan dalam analisis adalah benefit dan cost yang telah dipresent valuekan. Rumus yang digunakan adalah :

$I R R=i^{\prime}+\left[\frac{N P V '}{N P V^{\prime}+N P V^{\prime \prime}}\right] x\left(i^{\prime \prime}-i^{\prime}\right)$

(Prawirokusumo, 1990)

Keterangan :

NPV' = PV yang positif

NPV" = NPV yang negatif

i' = tingkat bunga yang menghasilkan NPV positif

i” = tingkat bunga yang menghasilkan NPV negatif

Suatu usaha apabila nilai IRR $>$ social discount rate, maka usaha tersebut akan layak dan apabila nilai IRR < social discount rate, maka proyek tersebut tidak akan layak (Pudjosumartono, 1995).

\section{Analisis Sensitivitas}

Analisis sensitivitas dilakukan karena adanya pengaruh perubahan harga anak berdasarkan umur penjualan pedet 18 bulan terhadap nilai NPV, BCR maupun IRR.

\section{Batasan Operasional}

Peternak yang diambil sebagai sampel dalam penelitian adalah peternak yang mengusahakan pembibitan sapi potong dengan memiliki induk yang telah beranak minimal 1 ekor dan telah dipelihara minimal 1 tahun. Perhitungan berdasarkan umur investasi 7 tahun dengan discount factor $12 \% /$ tahun sesuai dengan tingkat bunga yang berlaku pada usahatani ternak tersebut. Perhitungan produksi meliputi produk pokok berupa penjualan pedet dan produk sampingan berupa penjualan kotoran. Opportunity cost tenaga kerja yang tidak dibeli.

\section{HASIL DAN PEMBAHASAN}

\section{Identitas Peternak}

\section{Umur peternak}

Umur peternak sapi potong di lokasi penelitian berkisar antara 25 sampai 80 tahun dengan rata-rata 50 tahun. Umur peternak digolongkan menjadi 3 kelompok yaitu petani taruna yang berusia antara 15 sampai 25 tahun, petani muda yang berusia antara 25 sampaiv44 tahun dan petani dewasa yang berusia diatas 45 tahun (Soegiharto, 2004).

Berdasarkan penelitian bahwa $66,33 \%$ peternak berusia di atas 45 tahun. Menurut Soegiharto (2004) bahwa sektor pertanian menunjukkan tren aging agriculture, yaitu suatu kondisi dimana tenaga kerja yang berada di pertanian adalah tenaga kerja berusia lanjut.

\section{Tingkat Pendidikan Peternak}

Hasil penelitian menunjukkan bahwa peternak sebagian besar berpendidikan cukup tinggi karena 55\% sudah mengenyam pendidikan 9 tahun. Tingkat pendidikan peternak tersebut berpengaruh terhadap manajemen peternakan yang dilakukan. Pendidikan peternak menggambarkan kemampuan mengelola ternak sapi. Menurut Mosher (1987), tingkat pendidikan memiliki peran penting dalam memahami penggunaan teknologi untuk dapat meningkatkan produktivitas usaha pertanian karena dengan semakin tinggi tingkat pendidikan maka akan lebih mudah memahami dan menerapkan teknologi baru.

\section{Pekerjaan Peternak}

Pekerjaan utama masyarakat sebagian besar adalah petani sebesar 68,33\%. Peternak mengusahakan pembibitan sapi potong hanya sebagai pekerjaan sampingan yang berguna untuk membantu menambah penghasilan keluarga sehingga dapat meningkatkan taraf hidup peternak.

Aspek Teknis Pembibitan Sapi Potong 


\section{Sapi Bibit}

Induk yang dipelihara peternak di lokasi penelitian adalah bangsa sapi Peranakan Simmental 25 ekor, Peranakan Ongole 18 ekor, dan Peranakan Limousine 17 ekor. Alasan peternak memilih bangsa sapi tertentu antara lain: mudah memelihara karena pakan yang dibutuhkan relatif sedikit sehingga mereka mampu menyediakannya setiap hari; alasan lainnya adalah untuk penyediaan pakan tidak menjadi masalah karena memiliki cadangan pakan yang cukup baik hijauan maupun jerami dan konsentrat sehingga memilih bangsa sapi yang pertumbuhannya relatif cepat walaupun membutuhkan pakan yang relatif lebih banyak. Sapi induk yang dimiliki oleh responden telah beranak berkisar 2 sampai 7 kali.

\section{Pakan, Kandang dan Sewa Lahan}

Pada umumnya sapi-sapi dipelihara secara intensif yaitu dikandangkan sepanjang hari dengan disediakan pakan yang cukup. Pakan yang diberikan berupa hijauan dan konsentrat. Sebagian besar peternak memelihara ternaknya dengan sistem kandang kelompok yang dibangun dalam suatu lokasi dengan luas kaplingan yang sama. Bagi peternak yang memiliki skala kepemilikan diatas rata-rata maka mereka akan memerlukan lebih dari satu lokal kaplingan. Iuran dan sewa lahan yang ditetapkan masing-masing kelompok berbeda-beda mulai dari Rp 1.000,00 hingga Rp 100.000,00 pertahun.

\section{Koefisien Teknis}

Koefisien teknis calving interval dan umur penjualan pedet akan berpengaruh pada penerimaan dan biaya produksi. Berdasarkan data primer hasil survei, koefisien teknis disajikan seperti Tabel 2.

Tabel 2. Koefisien Teknis Usaha Pembibitan Sapi Potong di Kabupaten Sleman

\begin{tabular}{lccc}
\hline \hline Koefisien teknis & PO & $\begin{array}{c}\text { Peranakan } \\
\text { Simmental }\end{array}$ & $\begin{array}{c}\text { Peranakan } \\
\text { Limousine }\end{array}$ \\
\hline Calving Interval & $17,78 \pm 1,40 \mathrm{bln}$ & $16,92 \pm 1,44 \mathrm{bln}$ & $16,24 \pm 1,44 \mathrm{bln}$ \\
Penjualan pedet & $9,76 \pm 4,91 \mathrm{bln}$ & $7,20 \pm 4,00 \mathrm{bln}$ & $7,91 \pm 5,36 \mathrm{bln}$ \\
\hline
\end{tabular}

Sumber : Data primer terolah, 2007

\section{Aspek Finansial Usahatani Pembibitan Sapi Potong}

\section{Investasi Usahatani Pembibitan Sapi Potong}

Untuk mengetahui lebih jelas
besarnya masing-masing komponen investasi berdasarkan jenis sapi maka disajikan Tabel 3.

Tabel 3. Investasi Usahatani Pembibitan 2 Ekor Induk Sapi/Tahun di Kab. Sleman

\begin{tabular}{lrcc}
\hline \hline Komponen & \multicolumn{3}{c}{ Nilai investasi (Rp) } \\
\cline { 2 - 4 } investasi & \multicolumn{1}{c}{ PO } & Peranakan Simmental & Peranakan Limousine \\
\hline Kandang & 1.555 .556 & 2.304 .000 & 1.220 .588 \\
Sapi bibit & 10.834 .556 & 13.045 .600 & 11.860 .235 \\
Peralatan & 387.582 & 289.320 & 300.354 \\
\hline \multicolumn{1}{c}{ Total } & 12.777 .694 & 15.638 .920 & 13.381 .177 \\
\hline
\end{tabular}

Sumber : Data primer terolah, 2007

Pada Tabel 3 terlihat bahwa biaya investasi terbesar adalah jenis sapi Peranakan Simmental. Besarnya nilai investasi tersebut disebabkan oleh tingginya biaya yang dikeluarkan peternak untuk bibit dan pembuatan kandang. Variasi material 
yang digunakan dalam pembuatan kandang antara peternak satu dengan peternak lain berbeda-beda, tergantung kemampuan modal yang dimiliki peternak.

\section{Biaya Operasional Usahatani Pembibitan Sapi Potong}

Biaya operasional pada usahatani pembibitan sapi potong ini diperhitungkan secara tunai dan nontunai yang dinilai berdasarkan opportunity costnya. Biaya operasional berdasarkan jenis sapi dapat dilihat pada Tabel 4.

Tabel 4. Biaya Operasional Usaha Tani Pembibitan 2 Ekor Induk/Thn di Kab. Sleman

\begin{tabular}{|c|c|c|c|}
\hline \multirow{3}{*}{$\begin{array}{c}\text { Komponen } \\
\text { biaya operasional }\end{array}$} & \multicolumn{3}{|c|}{ Nilai biaya operasional (Rp) } \\
\hline & PO & Peranakan & Peranakan \\
\hline & & Simmental & Limousine \\
\hline Iuran & 2.667 & 3.320 & 3.000 \\
\hline Sewa lahan pakan & 1.944 & 10.800 & 11.324 \\
\hline Sewa lahan kandang & 29.639 & 38.120 & 28.824 \\
\hline Konsentrat & 2.292 .200 & 2.252 .780 & 2.293 .059 \\
\hline IB & 64.445 & 58.286 & 38.067 \\
\hline Kesehatan & 8.444 & 5.920 & 6.118 \\
\hline Obat-obatan & 19.194 & 16.020 & 16.735 \\
\hline Tenaga kerja & 348.074 & 270.328 & 298.575 \\
\hline Peralatan & 14.333 & 19.180 & 14.412 \\
\hline Total & 2.780 .940 & 2.674 .754 & 2.710 .114 \\
\hline
\end{tabular}

Sumber : Data primer terolah, 2007

Berdasarkan Tabel 4 menunjukkan bahwa biaya operasional untuk sapi pembibitan tidak berbeda jauh untuk tiga jenis sapi yaitu berkisar $\mathrm{Rp} 2.674 .754,00$ sampai dengan Rp 2.780.940,00. Biaya operasional pada usahatani pembibitan sapi potong terbesar adalah terletak pada biaya pakan terutama konsentrat. Sesuai dengan pendapat Prawirokusumo (1990) bahwa biaya pakan biasanya terbesar dalam usaha peternakan yaitu berkisar antara 60-80\% dari total biaya.

\section{Penerimaan usahatani pembibitan sapi potong}

Pada usaha tani pembibitan sapi potong ini penerimaan peternak berasal dari penjualan pedet sebagai produk pokok dan pupuk kandang sebagai produk sampingan yang dihasilkan oleh peternak serta nilai induk afkir.

\section{Analisis Sensitivitas}

Analisis sensitivitas pada usahatani pembibitan sapi potong ini berdasarkan perubahan umur penjualan pedet. Untuk koefisien teknis yang digunakan pada analisis sensitivitas usahatani pembibitan sapi potong seperti tersaji pada Tabel 5 .

Tabel 5. Koefisien Teknis Analisis Sensitivitas Usahatani Pembibitan Sapi Potong

\begin{tabular}{lccc}
\hline Koefisien Teknis & PO & Peranakan Simmental & Peranakan Limousine \\
\hline Calving interval & 15 bulan & 15 bulan & 15 bulan \\
Penjualan pedet & 18 bulan & 18 bulan & 18 bulan \\
BB sapi 18 bln & $+=185 \mathrm{~kg}$ & $+=250 \mathrm{~kg}$ & $q=250 \mathrm{~kg}$ \\
& $\hat{O}=250 \mathrm{~kg}$ & $\hat{O}=300 \mathrm{~kg}$ & $\hat{O}=300 \mathrm{~kg}$ \\
Mortalitas & $2 \%$ & $2 \%$ & $2 \%$ \\
Harga/kg BB & $\mathrm{Rp} 19.000,00$ & $\mathrm{Rp} 19.000,00$ & $\mathrm{Rp} 19.000,00$ \\
\hline
\end{tabular}

Sumber : Data primer terolah, 2007 
Umur penjualan pedet yang digunakan adalah 18 bulan. Hal ini disumsikan bahwa umur 18 bulan merupakan umur pertama kali kawin ternak sapi sehingga dapat digunakan sebagai sapi bibit untuk betina dan jantan sebagai sapi bakalan. Hasil analisis sensitivitas pada usahatani pembibitan sapi potong disajikan pada Tabel 6.

Tabel 6. Analisis Sensitivitas pada Umur Penjualan Pedet 18 Bulan

\begin{tabular}{lccc}
\hline Analisis & \multicolumn{3}{c}{ Hasil analisis } \\
\cline { 2 - 4 } sensitivitas & PO & Peranakan Simmental & Peranakan Limousine \\
\hline NPV & Rp. 8.048.353,00 & Rp 13.030.337,00 & Rp 14.443.576,00 \\
BCR & 1,49 & 1,67 & 1,84 \\
IRR & $22,72 \%$ & $26,38 \%$ & $29,70 \%$ \\
\hline
\end{tabular}

Sumber : Data primer terolah, 2007

Berdasarkan Tabel 10 terlihat bahwa hasil analisis sensitivitas dengan asumsi ada perbaikan manajemen sehingga calving interval 15 bulan dan umur penjualan pedet 18 bulan pada usahatani pembibitan ketiga jenis sapi tersebut layak untuk dijalankan karena NPV bernilai positif, BCR $>1$ dan IRR $>$ discount factor.

\section{KESIMPULAN}

Hasil analisis sensitivitas dengan asumsi ada perbaikan manajemen sehingga calving interval 15 bulan dan umur penjualan pedet 18 bulan pada usahatani pembibitan sapi pembibitan sapi potong layak untuk dijalankan dengan nilai kelayakan terbaik adalah jenis sapi Peranakan Limousine, selanjutnya Peranakan Simmental dan PO. Nilai NPV, IRR dan BCR pada sapi Peranakan Simmental berturut-turut adalah $\quad \mathrm{Rp}$ 13.030.337,00; 26,38\% dan 1,67. Nilai NPV, IRR dan BCR pada sapi Peranakan Limousine berturut-turut adalah $\mathrm{Rp}$ $14.443 .576,00 ; 29,70 \%$ dan 1,84. Untuk sapi PO memiliki nilai NPV, IRR dan BCR berturut-turut sebesar $\mathrm{Rp}$ 8.048.353,00; $22,72 \%$ dan 1,49 .

\section{DAFTAR PUSTAKA}

Ditjen Peternakan. 2006. Statistik Peternakan. Direktorat Jenderal
Peternakan. Departemen Pertanian RI, Jakarta.

Gittinger, J.P. 1986. Analisa Ekonomi Proyek-Proyek Pertanian. UI-Press, Jakarta.

Irfan, Z. et al. 2006. Program Rintisan dan Akselerasi Pemasyarakatan Inovasi Teknologi Pertanian (Prima Tani) di Panampuang, Kabupaten Agam, Propinsi Sumatera Barat. Balai Pengkajian Teknologi Pertanian, Sumatera Barat.

Kadariah, L. Karlina dan C. Gray. 1999. Pengantar Evaluasi Proyek. Fakultas Ekonomi. Universitas Indonesia, Jakarta.

Mosher, A.T. 1987. Menggerakkan dan Membangun Pertanian, Syarat-Syarat Pokok Pembangunan dan Modernisasi. CV. Yasaguna, Jakarta.

Prawirokusumo, S. 1990. Ilmu Usaha Tani. Edisi I. BPFE, Yogyakarta.

Pudjosumartono, M. 1995. Evaluasi Proyek, Uraian Singkat dan Soal Jawab. Liberty, Yogyakarta.

Soegiharto, S. 2004. Potret Tenaga Kerja di Sektor Pertanian. Kapus Litbang Ketransmigrasian-Balitfo, Jakarta.

Sugiyono. 2006. Metode Penelitian Bisnis. Cetakan 9. CV Alfabeta. Bandung. Susieni, A. 2003. Studi Kelayakan Bisnis. Cetakan 2. Penerbit Andi, Yogyakarta. 